\title{
A self-paced-reading study on the effects of structured input and textual enhancement on the acquisition of the Italian subjunctive of doubt
}

\author{
Gaia Chiuchiù and Alessandro Benati
}

\begin{abstract}
The present study investigates the effects of structured input and textual enhancement on the acquisition of the Italian subjunctive of doubt using a selfpaced reading test. The main questions of this study are: (1) Would L2 learners exposed to structured input and textual enhancement demonstrate sensitivity to violations of the Italian subjunctive of doubt as measured by a self-paced reading test? (2) Would L2 learners exposed to structured input and textual enhancement demonstrate the ability to comprehend sentences containing the subjunctive of doubt? Eighteen Chinese (L1) subjects learning Italian in a private school were randomly assigned to two instructional groups: structured input ( $\mathrm{n}=9)$; and textual enhancement $(\mathrm{n}=9)$. Neither instructional treatments included explicit information. The main results from the self-paced reading task indicated that only the structured input group showed higher sensitivity to violations, and this group improved from pre-test to post-test in the ability to comprehend sentences containing the target feature under investigation.
\end{abstract}

KEYWORDS: STRUCTURED INPUT; TEXTUAL ENHANCEMENT; ITALIAN SUBJUNCTIVE OF DOUBT; SELF-PACED READING

\section{$\overline{\text { Affiliations }}$}

Gaia Chiuchiù: University of Portsmouth, UK.

email: UP867866@myport.ac.uk

Alessandro Benati: The University of Hong Kong, Hong Kong.

email: abenati@hku.hk 


\section{Background}

The processing problem of non-meaningfulness, redundancy and location

Input processing (VanPatten 1996, 2004a, 2015a) refers to the processes by which L2 learners make the initial connection between a grammatical form and its meaning. As they process input, L2 learners are driven to look for the message (meaning), and they are more likely to process meaningful non-redundant grammatical forms before non-meaningful and redundant forms (VanPatten 2004a). Subjunctive mood verbal morphology is a linguistic item that is non-meaningful and redundant in sentences that express doubt and opinion in Italian and other Romance languages.

L2 learners use the subjunctive mood markings on the verb in a subordinate dependent clause when the verb of the main clause expresses doubt or opinion. That the verb form is buried in the latter part of the sentence presents learners with another processing problem, its location (VanPatten 2004a). L2 learners tend to process items in sentence initial position before those in final position and those in medial position. The following two sentences demonstrate the processing problems learners encounter with subjunctive mood morphology.

(1) Dubito che Stefano sia intelligente (I doubt that Stefano is intelligent).

So che Stefano è intelligente (I know that Stefano is intelligent).

The meaning of the verbs Dubito and So trigger the forms sia and è, respectively. Sia and è mean exactly the same thing, is. Finally, the position of the subjunctive verb form near the middle of the sentence puts it in a less preferred processing location. How do we structure the input so that learners are forced to process this form?

Lee and Benati (2007) compared two modes of delivering processing instruction and meaning-based output instruction on the acquisition of Italian and French subjunctive of doubt forms. Results from this study indicated that processing instruction is successful at altering the way L2 learners process and interpret sentences containing French and Italian subjunctive of doubt forms.

\section{Offline measures of structured input (enhanced and unenhanced)}

Empirical research has been conducted to measure the offline effects of enhanced versus unenhanced structured input.

Lee and Benati (2007) carried out an empirical study comparing the effects of enhancing structured input practice both aurally and textually. 
Structured input is a type of manipulated input where L2 learners are forced to process the targeted form in the input and connect it to its meaning. In their study, they addressed the question of whether learners make greater grammatical gains in Italian noun-adjective agreement by performing structured input activities in which the targeted adjective form is enhanced textually/aurally, as compared with performing structured input activities without enhanced forms as measured by both form interpretation and form production tests. The main findings of this study indicated that enhanced and unenhanced structured input activities proved equally effective in promoting grammatical gains in Italian noun-adjective agreement.

Lee and Benati (2007) also compared the performance of L2 learners who received enhanced structured input, unenhanced structured input and no instruction on the acquisition of Japanese past tense forms. The results of this study revealed that enhanced and unenhanced structured input are equally effective in helping learners process word-final, sentencefinal verb morphology.

Agiasophiti (2013) carried out an experimental study comparing the effects of enhanced and unenhanced structured input practice on the acquisition of case marking in German. She addressed the question of whether learners make greater grammatical gains on case marking in German by performing enhanced or unenhanced structured input activities, and whether individual differences - such as gender - would have an effect on the acquisition of the target structure. The main findings of this study revealed no significant difference between the scores of groups treated with enhanced or unenhanced input. Enhanced and unenhanced structured input proved equally effective in promoting grammatical gains on German case marking.

\section{Offline measures of structured input versus textual enhancement}

There is no empirical research comparing structured input versus textual enhancement. Marsden (2006) compared processing instruction and a type of 'enriched input', where attention to form and meaning was not necessary. She addressed the question as to whether focusing on form to process meaning is an essential feature in language acquisition, and whether proficiency levels would have an impact on the necessity of making formmeaning connections. The target language of the experiment was verbal inflections for number, person and tense (present and past time) in French. L2 learners tend to interpret lexical items before grammatical items when they both provide the same semantic information. Overall results indicated that the processing instruction group performed better than the enriched

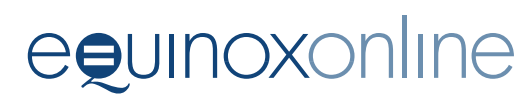


input group on the interpretation tasks (listening and reading). Processing instruction leads to greater learning gains than the enriched textual enhancement exposure, no matter the level of proficiency of the learners.

\section{Online measures (self-paced reading) of structured input}

There is no empirical research measuring the effects of structured input using an online measurement such as self-paced reading. However, Henry (2015) compared the effects of processing instruction (structured input and explicit information about the target feature) with traditional instruction on the acquisition of German accusative case markers. Henry tested German object-first sentences, which L2 learners tend to misinterpret as subject-first sentences due to reliance on the First Noun Principle (FNP). He administered a processing instruction (and a processing instruction treatment + prosody) treatment that pushed learners to rely on case-marked determiners instead of word order for information about grammatical roles. He also included a third treatment (traditional instruction) that reflected more traditional grammar instruction. Prior to and after instruction, participants completed a self-paced reading task in which they read subject-verb-object (SVO) and object-verb-subject (OVS) sentences phrase by phrase. Compared with learners who received traditional instruction, learners who received processing instruction (and processing instruction + prosody) had longer reading times on the critical noun phrases (NPs) after instruction, which suggests that processing instruction pushed learners to direct overt attention to NPs (presumably to attend to the case-marked determiners). However, reading times on case-marked NPs did not differ between SVO and OVS sentences, as was expected if learners were using case markings to override the FNP online. The main results of this study showed that the processing group outperformed the traditional instruction group on an offline comprehension task, but there were no differences between the two groups on the self-paced reading measure.

\section{The role of structured input}

Structured input practice pushes L2 learners to process the form or structure during activities in which the input is manipulated in particular ways to push learners to become dependent on form to get meaning. As outlined by Wong (2004:35), processing instruction 'pushes learners to abandon their inefficient processing strategies for more optimal ones so that better form-meaning connections are made'.

In a sentence such as Penso che Paolo sia un buon giocatore (I think that Paul is a good player), the easiest forms to process are those located in

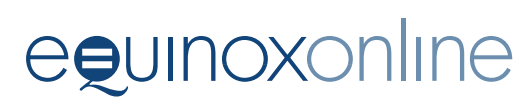


salient positions, specifically, initial position (Penso) within an utterance. The second easiest forms to process occur in the other salient position, utterance-final position (un buon giocatore). Finally, the most difficult forms to process are those that occur in utterance-medial position (sia). We tend to pay attention to what comes first (primacy) and what comes last (recency). Initial and final positions are privileged in terms of processing. Structured input practice should direct learners' attention to the subjunctives forms in medial position, as they have to decide if the speaker is expressing certainty about the statements or is expressing a value judgement about the statements.

\section{Motivation and research questions for the present study}

A growing body of research has compared the effects of enhanced structured input versus unenhanced structured input. The main findings of this branch of research demonstrated that structured input practice is effective regardless of the way in which it is delivered. There is no empirical research comparing the effects of structured input versus textual enhancement. Furthermore, there has been only one study carried out to measure the effectiveness of processing instruction when measured through a self-paced reading task. No previous study has been conducted to measure the effects of structured input when a self-paced reading task is one of the measurements.

The use of a self-paced reading task could provide - in addition to the large database of research available using offline pre- and post-test designs to measure the relative effects of structured input practice - more refined information about moment-by-moment language processing and comprehension. Based on previous research in this field, the aim of the present study is twofold: (1) to compare the effects of structured input and textual enhancement by measuring sensitivity to violations; (2) to measure possible differences in reading comprehension. Based on the main aims of this study and the specific intention to compare structured input and traditional instruction on the acquisition of the Italian subjunctive of doubt, two specific questions were formulated.

Q1: Would L2 learners exposed to structured input and textual enhancement demonstrate sensitivity to violations of the Italian subjunctive of doubt as measured by a self-paced reading test?

Q2: Would L2 learners exposed to structured input and textual enhancement demonstrate the ability to comprehend sentences containing the subjunctive of doubt? 


\section{Design}

\section{Participants}

The participants of the present study were native speakers of Chinese attending a language programme in Italy. Only participants who completed all the phases of the experiment (pre-self-paced reading test, instructional period and post-self-paced reading test) were included in the study.

The final pool consisted of eighteen adult learners of Italian (18 years old and above). They were randomly assigned to two groups: structured input $(n=9)$; textual enhancement $(n=9)$. The number of the participants in the study was reduced to eighteen from an original pool of thirty-seven based on the following criteria: (a) participants' scores in the self-paced reading pre-tests; (b) only participants with no exposure to the target grammatical form before the beginning of the experiment; (c) only participants who were native speakers of Chinese were included; (d) participants who had attended all parts of the experiment.

Participants were administered a background questionnaire, in order to gather specific information on the characteristics of the original pool. All participants were informed of the nature of the experiment, the duration of the study, and the anonymity of the experimental procedures (e.g. data collection and storage). Participants taking part in this experimental study were asked to sign a consent form to meet the standard ethical issues.

\section{Target grammar feature}

The subjunctive was chosen as the target feature for a number of reasons. First, because of the processing principle (the Sentence Location Principle) investigated in this study. According to VanPatten (2002, 2004b), learners tend to process items in a sentence that are located in initial position before those in final position and those in medial position. This processing strategy has been investigated in previous studies (Farley 2001a, 2001b, 2004). In Italian, the subjunctive is located in the medial position, where it is least likely to be processed. In the sentence Non penso che parli bene italiano (I do not believe he/she speaks Italian well) the subjunctive inflection (the $-i$ of parli) is in the middle of the sentence, and the Sentence Location Principle predicts that learners will overlook the subjunctive inflection because it is not located in a more salient position. Second, because it is affected by another principle that might influence the processing of the acquisition of the Italian subjunctive in nominal clauses after expressions of doubt, the Lexical Preference Principle. This processing strategy has been investigated in many processing instruction studies (e.g. Benati 
2001; Cadierno 1995). VanPatten (2004b) states that learners will tend to rely on lexical items as opposed to grammatical form to find meaning when both encode the same semantic information. In a sentence such as Non penso che canti bene (I doubt that he/she sings), the non-affirmative phrase Non penso expresses doubt to the learner. Learners have no need to attend to the subjunctive verb ending (the $-i$ in canti) because it simply recommunicates the non-affirmation already expressed by the lexical items in the main clause. Third, because the matrix clause of subjunctive sentences carries meaning, whereas the verb form in the dependent clause is simply triggered. As a triggered verb form it carries no semantic meaning. The subjunctive verb form in the dependent clause can also be seen as a redundant non-meaningful form. Learners face two more processing problems captured by the Preference for Non-redundancy Principle and the Meaning-before-Non-meaning Principle (VanPatten 2004b). Finally, the subjunctive of doubt was chosen in consideration of the participants' L1, Chinese. In Chinese, there are no verbal inflections, either for person or for tense or for mode, but rather particles that carry the meaning of, for example, 'pastness'. Furthermore, Chinese L2 learners don't possess a grammatical feature conveying subjunctive of doubt forms which can be transferred from their L1.

\section{Instructional materials}

The instructional material was balanced in every way except for the type of practice the students received (i.e. structured input vs textual enhancement practice). During the instructional treatment, participants didn't receive any feedback on their performance and the target feature. Two sets of instructional materials were produced in which all the activities in terms of activity types and visuals were balanced. The exact same vocabulary (which consisted of highly frequent items) across the treatments was provided. An equal amount of practice with the target form in both sets of instructional materials was also provided. The two groups received no explicit information prior to practice regarding the target feature, so that the only difference between the treatments was limited to the nature of the practice (structured input vs textual enhancement).

\section{Structured input}

The material for structured input was developed on the basis of the guidelines for the construction of structured input activities presented by Lee and VanPatten (1995, 2003), VanPatten and Sanz (1995) and Farley (2005). The structured input treatment consisted of referential and affective structured

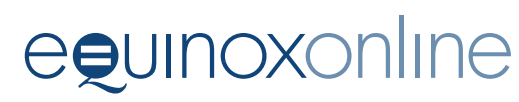


input activities. Structured input activities were developed to push L2 learners to focus on the Italian subjunctive of doubt. Learners were not asked to produce the correct verb mode, but were instead engaged in processing input sentences, so that they could circumvent wrong processing strategies and parse the elements in the sentence while interpreting meaning correctly. Structured input activities aimed at helping L2 learners not to overlook the subjunctive mode due to the following processing problems.

The subjunctive form is in the sentence medial position, where, according to the

Sentence Location Principle, forms are less likely to be processed.

The subjunctive form is made redundant by the lexical meaning expressed in the main clause verb, as described in the Lexical Preference Principle.

The treatment included ten activities: three referential structured input activities, two affective structured input activities and five activities that combined referential and affective types. Referential structured input activities were designed to encourage the participants to process the form while extracting its meaning, focusing on the subjunctive and not relying on the meaning of the verb in the main clause (see example in Figure 1).

\section{Parliamo di personaggi famosi in Italia.}

Ascolta la registrazione.

Sentirai l'inizio di una frase su fatti e opinioni su un personaggio famoso. Con le informazioni che senti, scegli la parte che completa la frase in modo corretto.

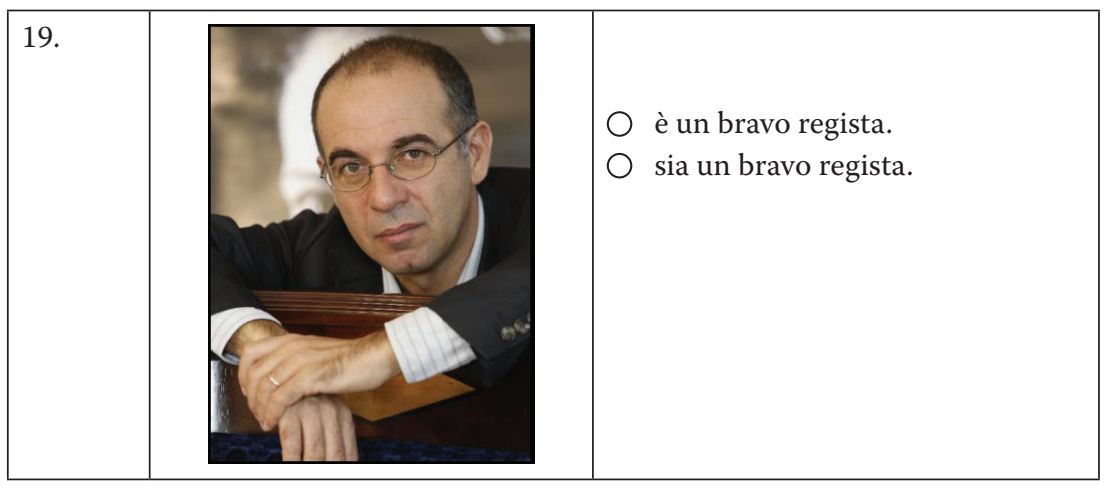

Sentence heard by participants: Non penso che Tornatore ... (I don't think that Tornatore ...).

Figure 1: Referential structured input activity.

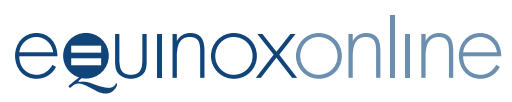


Una stilista famosa in tutto il mondo: Miuccia Prada

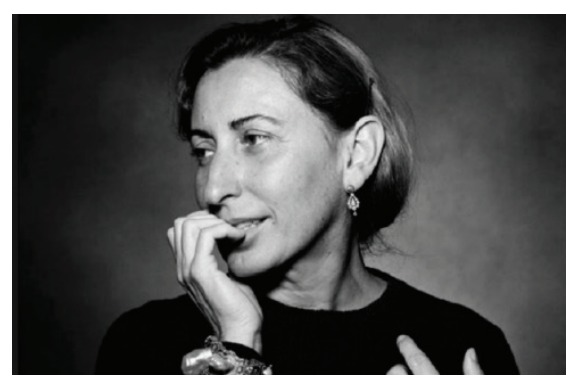

Ascolta la seconda parte di alcune informazioni su Miuccia Prada. Dopo l'ascolto scegli se sei d'accordo oppure no.

69. Penso che Miuccia Prada

[] Sì, sono d'accordo

[] No, non sono d'accordo

Figure 2: Affective structured input activity.

Each referential activity consisted of ten sentences. Participants listened to the sentences and chose one of the two options, indicating respectively doubt or certainty. Affective structured input activities were also designed, in order to encourage the participants to parse the form while extracting its meaning, but also to push them to interpret the form personally, by expressing agreement or disagreement with the content expressed in the input sentences

An example of affective structured input activity is provided in Figure 2.

The instructional material was delivered to the two groups via pencil and paper. No feedback was provided after each activity. In the structured input group, participants received a booklet of ten structured input reading comprehension tasks. For six of the ten tasks they received aural input. Participants had to interpret the phrases they heard or read by choosing one out of two clauses listed as options in the activity.

Textual enhancement

The textual enhancement group received a booklet with ten textual enhanced activities. Participants engaged in reading comprehension tasks where verbs in the subjunctive were enhanced. The material was developed on the basis of the guideline principles for the construction textual enhancement activities presented in Wong (2005). Textual enhancement is used to make particular features of written input more salient, with the aim 
of helping L2 learners notice these forms and make form-meaning connections. The target form is enhanced by visually altering its appearance in the text (italicised, emboldened, underlined). Oral input enhancement can also be provided by using special stress, intonation and gestures in spoken input. Designing input enhancement tasks is based on the following guideline principles: (a) choose a grammatical feature learners need to pay attention to; (b) highlight the feature in the text using a textual enhancement technique (e.g. emboldening, underlining); (c) keep learner's attention on meaning; (d) do not provide any metalinguistic explanation.

Textual enhancement is used to make particular features (in the examples below the subjunctive form in Italian) of written input more salient with the aim of helping learners to notice these forms. The target form was enhanced by visually altering (see example in Figure 3) its appearance in the text (in bold type). Only written input enhancement was provided.

\section{Vita da studenti}

Leggi i testi: descrivono uno studente cinese, uno studente italiano o tutti e due?

\section{Cerchial'immagine per "Italia,,Cina" o "Italia e Cina".}

1. Dubito che abbia un lavoro mentre studia e credo che abbia almeno due telefoni e un tablet. Tutti i giorni viaggia in treno per circa due ore, per andare all'università e seguire le lezioni. All'università non penso che scriva a mano i suoi appunti, ma credo che usi il tablet per scrivere appunti. Ha molti amici e non credo faccia sport. So che ama indossare vestiti firmati e penso che ami comprare quasi tutto online. Non credo che vada mai in un negozio perché ogni giorno riceve a casa dei pacchi. Va a lezione tutte le mattine e poi, dopo i corsi, passa molte ore a giocare con i giochi elettronici. Non ne sono sicura, ma credo che sia figlio unico.

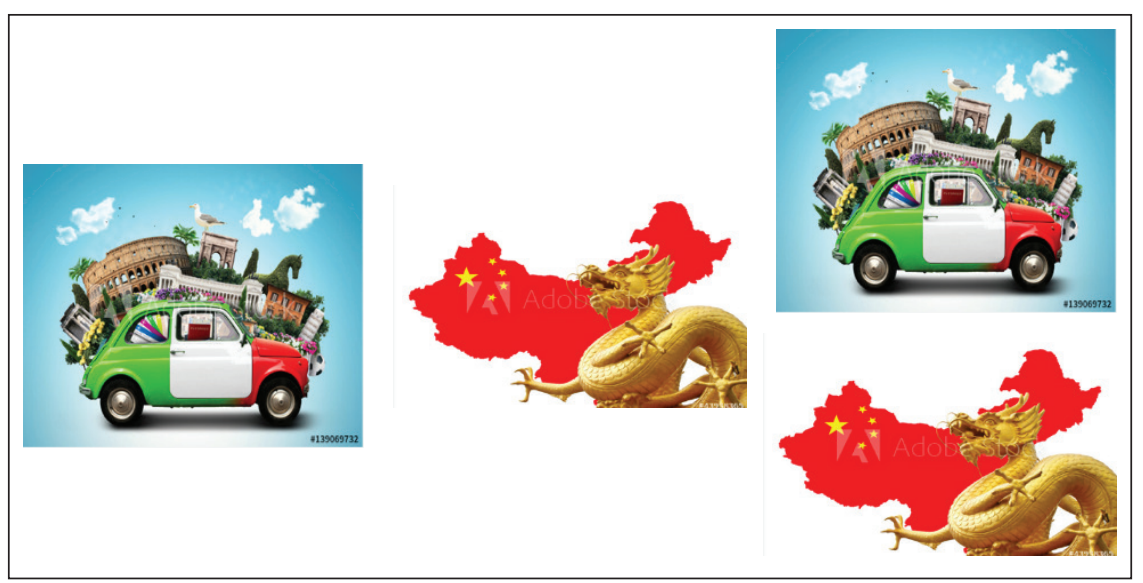

Figure 3: Textual enhancement activity. 
In both instructional groups, participants were never asked to produce sentences.

\section{Procedure}

Online tests were administered a week prior to the beginning of the instructional treatment and immediately after the treatment. Tests were delivered to the groups after a brief training session on practical instructions on how to complete the tests. Participants were tested individually using the software Paradigm. Each experiment was designed using two sets: set A and set B. Each student sat at one of the two computers available for the experiment to take the test. One computer was ready to display set A, the other set B. Both experiments started with instructions in Italian and Chinese on how to complete the test. The instruction received by participants consisted mainly in informing them how to use the buttons to reveal the parts of the sentences (see Figure 4). Students had to press the space bar to disclose the next part of the sentence and, once the last part of

Leggerai alcune parole che compongono una frase.

Usa la barra spaziatrice per far scorrere le parole.

你会读到一些组成句子的单词。

使用空格键移动单词。

Fai attenzione a capire il significato delle frasi perché qualche volta dovrai rispondere a delle domande di comprensione.

注意理解句义，因为有时你要回答理解类问题。

usa:

s per rispondere sì

$\mathrm{n}$ per rispondere no

f per rispondere forse

用:

$\mathrm{s}$ 表示是

$\mathrm{n}$ 表示否

$\mathrm{f}$ 表示也许

Figure 4: Instructions. 
the sentence was displayed, a further press of the space bar would display a comprehension question.

Comprehension questions had three possible answers: yes, no, maybe. Participants were informed that the buttons to be used were: $\mathrm{S}$, meaning $s i$ (yes); N, meaning no (no); F, meaning forse (maybe).

Participants were reminded to read the sentences silently, without articulating. The current study aimed at measuring solely the reading times while reading and comprehending a sentence. One week after the pretests, the two groups received the instructional treatments (two hours in total). Participants were provided with a booklet which included the tasks to be completed. After the instructional treatment the online post-test was administered.

\section{Self-paced reading test}

The online test was administered in a pre-test and immediate post-test design. Participants were tested individually one week prior the treatment and immediately after the treatment. Participants read the instructions on the first slide of the experiment and completed the test individually. Online measurements have recently been used to investigate L2 learners' intuitive and immediate reactions, mirroring their processing behaviour and the effects of the pedagogical interventions they are exposed to. Self-paced reading is one of the online research techniques applied in non-native second language research (Jegerski and VanPatten 2014). It measures the participant's reaction to problems such as ambiguity and violations during real-time computation. Self-paced tests are administered via computer. Each participant reads on a computer screen parts of a sentence. Participants use a button to make the part of the sentence just viewed and comprehended disappear and to simultaneously reveal the next part. Participants are never shown the whole sentence on the screen.

For example, participants will see on the screen the Italian ungrammatical sentence Immagino che il professore entra* in aula in orario initially in this fashion:

After pressing the designed button, the first part of the sentence will be revealed:

Immagino che

Similarly, every subsequent press of the designed button will reveal the following parts of the sentence and hide the previous ones: 
in aula

in orario

After each press of the button, the software records the reading time for that part of the sentence. As pointed out by Marsden, Thompson and Polonsky (2018:3), 'underlying this technique is an assumption that participant reaction times indicate their knowledge of and/or sensitivity to linguistic phenomena relative to other phenomena.

After revealing the last part of the sentence, the next press of the button brings onto the screen a comprehension question about the general content of the previous sentence displayed (for example: Il professore è in ritardo? Si / No / Forse).

Comprehension questions ensure that participants focus on the meaning of each sentence.

The method just described was used in this study and it is is known as non-cumulative or moving window. It allows the researcher to target segments of the sentence showing a violation and collect each participant's reading times. Parts of the sentences in a self-paced task are named regions. In this study, the regions of interest are region 3, which shows a violation in the subjunctive, and the following region 4 . Regions scoring higher times describe a more effortful task for the participant.

Regions:

\begin{tabular}{c|c|c|c|c}
\hline 1 & 2 & 3 & 4 & 5 \\
Immagino che & il professore & entra & in aula & in orario.
\end{tabular}

In this study, the regions of interest are region 3, showing a violation, and region 4 . The regions of interest are the segments showing a verb in the indicative mood in a sentence where the subjunctive is needed. The analysis of reading times informs the researcher of the participants' sensitivity to violations. In the present study, the two instructional groups' reading times were recorded before and after the treatment, in order to explore the effects of each pedagogical intervention. Each self-paced reading test in this study included twenty experimental sentences along with their comprehension questions, and twenty fillers followed by ten comprehension questions. Paradigm was the software used to set up the self-paced reading tests. Each self-paced reading test was divided into two sets: A and B. 
As previously stated, each set was made of forty stimuli, including twenty distractors, ten sentences in condition (a) not showing a violation, and ten sentences in condition (b) showing a violation. Each experimental sentence is followed by a comprehension question (see example below).

(a) Penso che $\backslash$ Piero $\backslash$ vada $\backslash$ al lavoro $\backslash$ in treno. (in set A)

(b) Penso che $\backslash$ Piero $\backslash$ va* $\backslash$ al lavoro $\backslash$ in treno. (in set B)

Comprehension question: Pietro lavora? Sì / No / Forse

Participants pressed the $\mathrm{S}$ or $\mathrm{N}$ or $\mathrm{F}$ button on the response pad to indicate the correct response.

Each experimental sentence in the self-paced reading task was followed by a comprehension question, in order to ensure that participants read the sentence for meaning.

In each set, only half of the comprehension questions tested comprehension of the target form. Each test displayed ten comprehension questions, comprising five comprehension questions displayed in set $\mathrm{A}$, and five in set B. An example of questions measuring comprehension is given below, for the sentence in condition (a).

(a) Immagino che $\backslash$ la banca $\backslash$ sia $\backslash$ aperta $\backslash$ tutto il giorno. (in set B)

(b) Immagino che $\backslash$ la banca $\backslash \mathrm{è}^{*} \backslash$ aperta $\backslash$ tutto il giorno. (in set A)

Comprehension question: Oggi la banca è aperta? Sì / No / Forse

The expression of doubt/opinion can be rendered in Italian by the verb in the subjunctive, or by the lexical form forse (maybe), followed by the verb in the indicative mode. The correct answer to the experimental sentence in condition (a) is: forse (maybe). In comprehension questions targeting the Italian subjunctive, forse (maybe) scored one point, the other answers scored zero. While participants read the sentences, the software recorded the reading times of each part of the sentence, in milliseconds. As Keating and Jegerski (2015) recommend, in this study reaction times for responses to comprehension questions were analysed. The assumption is that reading times would reveal the parts of the sentences that cause a processing problem. A self-paced reading test engages participants to read for meaning. If participants don't show a processing problem when encountering a violation, it is good evidence that the knowledge of the target feature is not 'automatically activated' (Jiang 2012:10). This author clarifies further as follows:

There are good reasons to think that explicit knowledge is minimally involved in performing this task. First, the task focuses the participants' attention

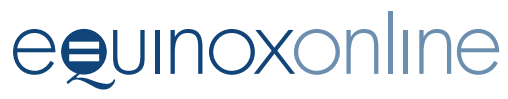


on comprehension rather than on grammatical accuracy, which makes the application of explicit knowledge less relevant. Second, this receptive reading task does not require productive use of L2, which further removes the motivation for applying explicit knowledge. Finally, the emphasis on the speed of performance and the transient nature of input display also discourage the application of explicit knowledge. (Jiang 2012:10)

After the experiment, the reading times for regions of interest were tabulated. Data were trimmed, removing reading times lower than 200 milliseconds (ms) and higher than $4000 \mathrm{~ms}$. Reading times lower than $200 \mathrm{~ms}$ would correspond to 'didn't read', while a reading time higher than 4000 ms would not give an insight on implicit knowledge (Henry 2015). Reading times of regions of interest were extracted, and the mean reading time was calculated for each participant, and then for each group. Then, for each group, pre-test and post-test reading times were compared.

A further analysis was conducted for reaction times and comprehension of sentences in condition (a). The time needed to answer comprehension questions targeting the grammatical feature were recorded and answers were scored. Reaction time analysis included only regions 3 and 4 of sentences in condition (a) that were correctly understood (i.e. which participants answered correctly, thus scoring one point).

\section{Results}

In order to address the two research questions of the present study, the means and standard deviations (descriptive analysis) for cumulative reading times and for reaction times to comprehension questions were calculated; $t$-tests were used to compare the performance of two experimental groups on the self-paced reading tests.

\section{Reading times}

Descriptive statistics for reading times in the structured input group (Table 1) and the textual enhancement group (Table 2) were calculated. The sum of the reading times for each participant in two critical regions (regions 3 and 4) of sentences in condition (b) were calculated. In each sentence, the reading time for region 3 shows the time needed to read the verb in condition (b) (i.e. showing a violation - the verb not in the subjunctive mode, but in the indicative mode), and the reading time for region 4 shows the time needed to read the following region, possibly affected by the sensitivity to violation in region 3 . Once the means for the reading times of the critical regions for each participant were calculated, the researcher calculated 
Table 1: Descriptive statistics for cumulative reading times (structured input).

\begin{tabular}{lll}
\hline & \multicolumn{2}{l}{ Structured input group } \\
\cline { 2 - 3 } & Mean reading time $(\mathrm{ms})$ & Standard deviation \\
\hline Pre-test & 1552.15 & 29.9538 \\
Post-test & 1814.19 & 38.2873 \\
\hline
\end{tabular}

Table 2: Descriptive statistics for cumulative reading times (textual enhancement).

\begin{tabular}{lll}
\hline & \multicolumn{2}{l}{ Textual enhancement group } \\
\cline { 2 - 3 } & Mean reading time $(\mathrm{ms})$ & Standard deviation \\
\hline Pre-test & 1665.57 & 37.2113 \\
Post-test & 1559.17 & 38.3727 \\
\hline
\end{tabular}

the means and standard deviation in each experimental group (structured input vs textual enhancement). The sum of the correct answers to the comprehension questions following the sentences in condition (a) (i.e. not showing a violation - the verb in the subjunctive mode) was calculated. Based on these results, the answer for the structured input group showed higher sensitivity to violations of the Italian subjunctive; their reading times increased by $17 \%$ after the treatment. In contrast, the mean for the textual enhancement group reading times decreased by $6 \%$, showing a slightly reduced sensitivity to violations after the treatment.

The $t$-test carried out on the pre- and post-test self-paced reading results, showed that for the structured input group the difference between the means was significant, $t(9)=-2683, p=0.004$. The difference between the means in the textual enhancement group was not significant, $t(9)=$ $-1263, p=0.44$.

Based on these statistical analysis results, the answer to our first research question is yes. L2 learners in the structured input group showed sensitivity to violations of the Italian subjunctive of doubt on the self-paced reading test.

Figure 5 indicates that the structured input group increased their sensitivity to violations, whereas the textual enhancement group did not.

Structured input activities had an impact on the participants' processing behaviour, increasing their level of implicit knowledge (Benati and Angelovska 2016; Hulstijn 2005).

In both structured input and textual enhancement tasks, the input is manipulated to make it more likely to be incorporated in the L2 developing system. In Schmidt's noticing theory (Schmidt 1990), it is only the input that has been consciously noticed and converted into intake. In contrast, 


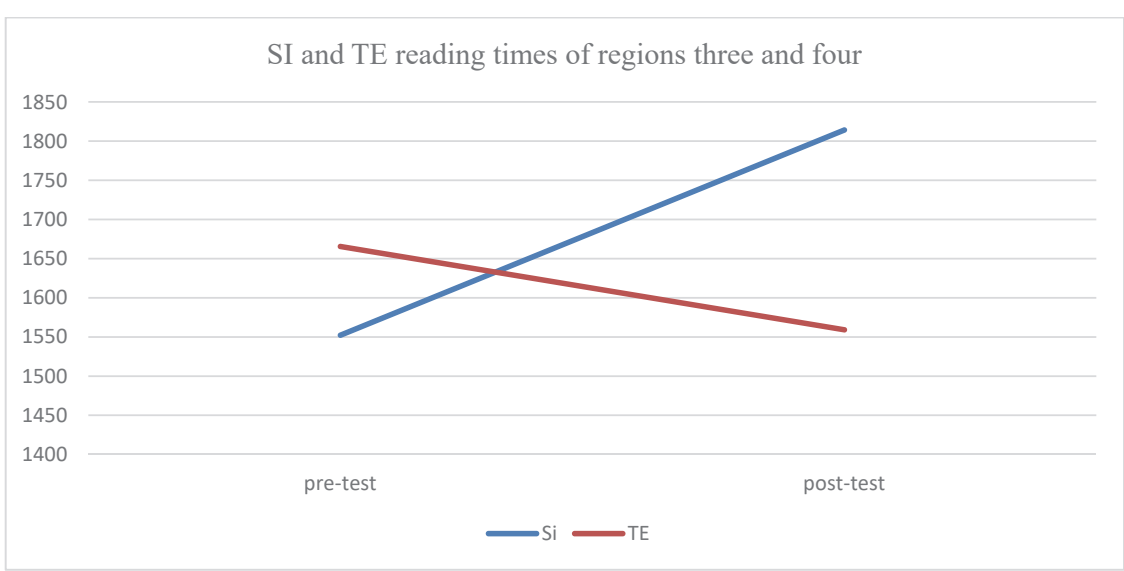

Figure 5: Structured input (SI) and textual enhancement (TE) reading times for regions 3 and 4 (in $\mathrm{ms}$ ).

other researchers following Tomlin and Villa's fine-grained analysis on attention (Tomlin and Villa 1994) assert that consciously noticing the form does not guarantee acquisition. Processing instruction is predicated on the input processing model, and its main component - structured input - is designed to facilitate acquisition because it pushes learners to process simultaneously form and meaning, not because of noticing the form alone. In this study, the structured input group showed increased reading times from pre-test to post-test; these results corroborate Lee and Benati's (2007) findings that structured input is successful at altering the way L2 learners process and interpret sentences containing Italian subjunctive of doubt forms, and that it does so more effectively than textual enhancement.

\section{Sentence comprehension reaction times}

Descriptive statistics were calculated for comprehension question reading times for the structured input group (Table 3) and the textual enhancement group (Table 4). The sum of the reaction times for each participant was calculated. Once the means of the reading times were calculated, the

Table 3: Descriptive statistics for comprehension question reading times (structured input).

\begin{tabular}{lll}
\hline & \multicolumn{2}{l}{ Structured input group } \\
\cline { 2 - 3 } & Mean reading time & Standard deviation \\
\hline Pre-test & 2032.34 & 72.5061 \\
Post-test & 1621.52 & 17.7812 \\
\hline
\end{tabular}


Table 4: Descriptive statistics for comprehension question reading times (textual enhancement).

\begin{tabular}{lll}
\hline & \multicolumn{2}{l}{ Textual enhancement group } \\
\cline { 2 - 3 } & Mean reading time & Standard deviation \\
\hline Pre-test & 1400.12 & 11.4701 \\
Post-test & 1375.35 & 22.0106 \\
\hline
\end{tabular}

researcher calculated the means and standard deviation for each experimental group (structured input vs textual enhancement), and the pre-test and post-test reading times were compared.

In order to examine the results obtained for sentence comprehension, $t$-tests were performed on the structured input versus textual enhancement groups. Results indicate that the structured input group comprehended sentences containing the target feature better than the textual enhancement group. The $t$-test for the structured input group demonstrated that the difference between means was significant, $t(9)=-1.349, p=0.000$. The $t$-test for the textual enhancement group showed that the difference between means was not significant, $t(9)=-1.142, p=0.56$.

Based on the statistical analyses presented in this section, the answer to the second research question in this study is yes. L2 learners in the structured input group showed that their ability to interpret sentences containing the Italian subjunctive of doubt increased in the self-paced reading test. The reading time taken to choose the correct answer in this group increased from pre- to post-test by around $20 \%$. The textual enhancement group did not improve.

L2 learners in the structured input group processed input in a more effective way than they would if they had been unable to circumvent the effects of wrong processing strategies described in the Sentence Location Principle and the Lexical Preference Principle. Structured input is predicated on the model of input processing as defined by VanPatten:

The model of input processing that informs PI attempts to delineate the major strategies (principles) involved in how learners parse sentences (compute basic structure in real time) and the problems in linking form with meaning during real-time comprehension. (2015b:106)

In this study, participants from the structured input group only show a change in their ability to process and comprehend the grammatical target form during real-time comprehension. 


\section{Summary of results}

The two main questions of the present study were as follows.

Q1: Would L2 learners exposed to structured input and textual enhancement demonstrate sensitivity to violations of the Italian subjunctive of doubt as measured by a self-paced reading test?

Q2: Would L2 learners exposed to structured input and textual enhancement demonstrate the ability to comprehend sentences containing the subjunctive of doubt?

Based on the results presented in the previous section, the answer to the first research question is positive. L2 learners in the structured input group showed sensitivity to violations of the Italian subjunctive of doubt on the self-paced reading test. The answer to the second question of this study is also affirmative. The statistical analysis clearly indicates that only the structured input group comprehended/interpreted correctly sentences containing the target feature. The reading times of the structured input group decreased from pre- to post-test, whereas those of the textual enhancement group did not. Overall, only participants in the structured input group showed a change in their processing behaviour.

\section{Discussion}

The overall results of the present study indicate that the structured input instructional treatment is effective at altering a number of processing problems (non-meaningfulness, redundancy and location) in the interpretation of sentences containing Italian subjunctive of doubt forms. Structured input practice is successful at circumventing processing constraints and ensures that L2 learners process sentences correctly and make appropriate form-meaning connections. The statistical analysis indicates that only the group exposed to structured input demonstrate sensitivity to violations of the Italian subjunctive of doubt as measured by a self-paced reading test. The same group was able to better comprehend sentences containing the target linguistic feature. The structured input treatment had an effect on the way learners process input. The textual enhancement treatment did not have similar effects.

One possible explanation for the results obtained in this experimental study can be found in the nature of structured input practice when compared with textual enhancement. Unlike textual enhancement where the input is enhanced, structured input practice requires a simultaneous focus on meaning and form. Textual enhancement may have a facilitative role for L2 learners in noticing (becoming aware of) something ('a form') in

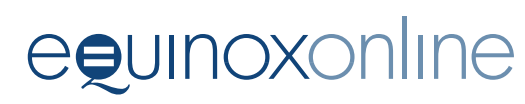


the input. However, there is nothing in the definition of 'noticing' related to the concept of form-meaning mappings. It seems that structured input practice guarantees that $\mathrm{L} 2$ learners make correct form-meaning mappings at input level.

The present study has pedagogical implications. One of the benefits of structured input is that it changes the way learners' brains work with linguistic input. Structured input practice offers the possibility to develop activities that are effective and change processing behaviours.

Future research using self-paced reading tests should examine the effects of structured input practice versus other instructional treatments and linguistic features before we can generalise the findings of this study. The present study does not provide individualised positive and negative feedback during the treatment phase. Future research should examine the effects of feedback type within a self-paced reading research framework. Do learners respond differently to the feedback?

Future research should include a bigger sample of participants and delayed self-paced reading post-tests. Such research should examine the effects of structured input over a two-month period. How long are the immediate post-test results sustainable? Two weeks? Four weeks? Six weeks? And can re-exposure during the post-test period provide an enhancing effect?

\section{Conclusions}

The present study was guided by two research questions. The results lead us to the following conclusions. Regarding the first research question, the results of this study clearly indicated that it was only the structured input group who showed sensitivity to violations of the Italian subjunctive of doubt when measured by the self-paced reading test. Regarding the second research question, participants in the structured input group demonstrated that the ability to interpret sentences containing the Italian subjunctive of doubt increased in the self-paced reading test. The reading time for choosing the correct answer in the structured input group increased from pre- to post-test.

Self-paced reading is a method adopted to determine learners' sensitivity to violations. Importantly, it can be used to measure underlying implicit knowledge or lack of it. The present study makes use of a sophisticated research design which uses measurements (tests) that attempt to test implicit knowledge and not explicit knowledge. The main implications of the findings of this study are twofold: (1) theoretically, this study provides online evidence of the effects of structured input in the acquisition 
of Italian subjunctive of doubt forms; (2) methodologically, it reiterates the importance of research measuring the effects of instructional treatment using online methods such as eye-tracking and self-paced tests to effectively and properly measure implicit knowledge. Future research can only make claims related to the effects of instruction, particularly on the rate of acquisition (not on the route of acquisition) if it adopts a method that measures implicit knowledge.

\section{About the author}

Gaia Chiuchiù is currently a PhD student at the University of Portsmouth. She is responsible for the activities of research, experimentation and programming at the Academia of Italian Language in Assisi. She is author and co-author of a number of textbooks for the teaching of Italian language.

Alessandro Benati is Director of CAES at The University of Hong Kong (HKU). He is known for his work in second language acquisition and second language teaching. $\mathrm{He}$ has published ground-breaking research on the pedagogical framework called processing instruction. He is a member of the REF Panel 2021 and Honorary Professor at the University of York SJ.

\section{Acknowledgements}

We would like to thank all the students who participated in the study. We also express our gratitude to our colleagues who read this paper and provided us with valuable comments and suggestions.

\section{References}

Agiasophiti, Z. (2013) Exploring possible effects of gender and enhanced vs. unenhanced processing instruction on the acquisition of case marking in L2 German. In J. Lee and A. Benati (eds) Individual Differences and Processing Instruction 153-84. Sheffield: Equinox.

Benati, A. (2001) A comparative study of the effects of processing instruction and output-based instruction on the acquisition of the Italian future tense. Language Teaching Research 5: 95-127. https://doi.org/10.1177/136216880100500202; https://doi. org/10.1191/136216801678766877

Benati, A. and Angelovska, T. (2016) Second Language Acquisition : A Theoretical Introduction to Real-World Applications. London: Bloomsbury Academic, an imprint of Bloomsbury Publishing.

Cadierno, T. (1995) Formal instruction from a processing perspective: an investigation into the Spanish past tense. Modern Language Journal 79(2): 179-93. https://doi. org/10.1111/j.1540-4781.1995.tb05430.x

Farley, A. P. (2001a) The effects of processing instruction and meaning-based output instruction. Spanish Applied Linguistics 5: 57-94.

Farley, A. P. (2001b) Authentic processing instruction and the Spanish subjunctive. His-

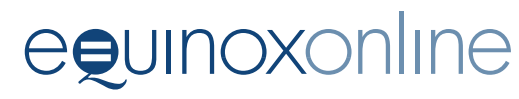


pania 84(2): 289-99. https://doi.org/10.2307/3657760

Farley, A. P. (2004) The relative effects of processing instruction and meaning-based output instruction. In B. VanPatten (ed.) Processing Instruction: Theory, Research, and Commentary 227-39. Mahwah, NJ: Lawrence Erlbaum.

Farley, A. P. (2005) Structured Input. New York: McGraw-Hill.

Henry, N. (2015) Morphosyntactic processing, cue interaction, and the effects of instruction: an investigation of processing instruction and the acquisition of case markings in L2 German. Unpublished doctoral dissertation, Pennsylvania State University, USA.

Hulstijn, J. (2005) Theoretical and empirical issues in the study of implicit and explicit language learning. Studies in Second Language Acquisition 27(2): 129-40. https:// doi.org/10.1017/S0272263105050084

Jegerski, J. and VanPatten B. (eds) (2014) Research Methods in Second Language Psycholinguistics. New York: Routledge. https://doi.org/10.4324/9780203123430

Jiang, N. (2012) Conducting Reaction Time Research in Second Language Studies. New York: Routledge. https://doi.org/10.4324/9780203146255

Keating, G. and Jegerski, J. (2015) Experimental designs in sentence processing research. Studies in Second Language Acquisition 37(1): 1-32. https://doi.org/10.1017/ S0272263114000187

Lee, J. and Benati, A. (2007) Delivering Processing Instruction in Classrooms and in Virtual Contexts: Research and Practice. London: Equinox.

Lee, J. and Benati, A. (2009) Research and Perspectives on Processing Instruction. Berlin: De Gruyter Mouton. https://doi.org/10.1515/9783110215335

Lee, J. and Benati, A. (eds) (2013) Individual Differences and Processing Instruction. Sheffield: Equinox.

Lee, J. and VanPatten, B. (1995) Making Communicative Teaching Happen. New York: McGraw-Hill.

Lee, J. and VanPatten, B. (2003) Making Communicative Teaching Happen (2nd edn). New York: McGraw-Hill.

Marsden, E. (2006) Exploring input processing in the classroom: an experimental comparison of processing instruction and enriched input. Language Learning 56: 50766. https://doi.org/10.1111/j.1467-9922.2006.00375.x

Marsden, E., Thompson, S. and Polonsky, L. (2018) A methodological synthesis of selfpaced reading in second language research. Applied Psycholinguistics 39(5): 861904. https://doi.org/10.1017/S0142716418000036

Schmidt, R. (1990) The role of consciousness in second language learning. Applied Linguistics 11(2): 129-58. https://doi.org/10.1093/applin/11.2.129

Tomlin, R. and Villa, V. (1994) Attention in cognitive science and second language acquisition. Studies in Second Language Acquisition 16(2): 183-203. https://doi. org/10.1017/S0272263100012870

VanPatten, B. (1996) Input Processing and Grammar Instruction: Theory and Research. Norwood, NJ: Ablex.

VanPatten, B. (2002) Processing instruction: an update. Language Learning 52(4): 755803. https://doi.org/10.1111/1467-9922.00203

VanPatten, B. (2003) From Input to Output: A Teacher's Guide to Second Language Acquisition. New York: McGraw-Hill.

VanPatten, B. (ed.) (2004a) Processing Instruction: Theory, Research, and Commentary. Mahwah, NJ: Lawrence Erlbaum. https://doi.org/10.4324/9781410610195

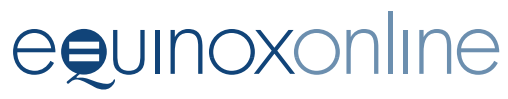


VanPatten, B. (ed.) (2004b) Input processing in second language acquisition. In B. VanPatten (ed.) Processing Instruction: Theory, Research, and Commentary 5-31. Mahwah, NJ: Lawrence Erlbaum. https://doi.org/10.4324/9781410610195

VanPatten, B. (2015a) Input processing in adult SLA. In B. VanPatten and J. Williams (eds) Theories in Second Language Acquisition 113-35. New York: Routledge. https://doi.org/10.4324/9780203628942

VanPatten, B. (2015b) Foundations of processing instruction. International Review of Applied Linguistics 53(2): 91-109. https://doi.org/10.1515/iral-2015-0005

VanPatten, B. and Sanz, C. (1995) From input to output: processing instruction and communicative tasks. In F. R. Eckman, D. Highland, P. W. Lee, J. Mileham and R. R. Weber (eds) Second Language Acquisition Theory and Pedagogy 169-85. Mahwah, NJ: Erlbaum.

Wong, W. (2004) Processing instruction in French: the roles of explicit information and structured input. In B. VanPatten (ed.) Processing Instruction: Theory, Research, and Commentary 187-205. Mahwah, NJ: Erlbaum.

Wong, W. (2005) Input Enhancement: From Theory and Research to the Classroom. New York: McGraw-Hill. 